\title{
Osseointegration Reduces Aseptic Loosening of Primary Distal Femoral Implants in Pediatric and Adolescent Osteosarcoma Patients: A Retrospective Clinical and Radiographic Study
}

\section{Clayton Welsh}

University of Central Florida

\section{Peyton Hull}

University of Central Florida

Teerin Meckmongkol

University of Central Florida

Aadil Mumith

University of Central Florida

John Lovejoy

University of Central Florida

Charles Giangarra

Marshall University

Melanie Coathup ( $\square$ Melanie.coathup@ucf.edu )

University of Central Florida

\section{Research Article}

Keywords: osteosarcoma, distal femoral replacement, osteolysis, extracortical bone formation

Posted Date: March 7th, 2022

DOI: https://doi.org/10.21203/rs.3.rs-1405160/v1

License: (9) (i) This work is licensed under a Creative Commons Attribution 4.0 International License. Read Full License 


\section{Abstract}

Aim

The challenge of distal femoral replacement (DFR) longevity remains a priority for orthopaedic oncologists as the overall survival and activity level of young patients with osteosarcoma continues to improve. This study hypothesised that increased extracortical osseointegration at the bone-implant shoulder will improve stress transfer adjacent to the implant, as evidenced by reduced cortical bone loss, radiolucent line progression and implant failure in young patients (<20-years) following DFR surgery.

\section{Methods}

Twenty-nine patients of mean age $13.09 \pm 0.56 y$ received a primary DFR. The clinical outcome of 11 CPS $\AA, 10$ GMRS $\AA$, 5 Stanmore $\AA$ and 3 Repiphysis $\AA$ implants were evaluated over a mean follow-up period of $4.25 \pm 0.55 y$. The osseous response to an implant shoulder composed of either a hydroxyapatitecoated grooved ingrowth collar (Stanmore $\AA$ ), a porous metal coating (GMRS $\AA$ ) or a polished metal surface (Repiphysis ${ }^{\circledR}$ ) was quantified radiographically.

\section{Results}

All $(100.0 \%)$ of the Stanmore ${ }^{\circledR}$ implants, $90.0 \%$ of GMRS $\AA, 81.8 \%$ of CPS $\AA$ and $33.3 \%$ of the Repiphysis ${ }^{\circledR}$ implants survived. Significantly increased extracortical bone and osseointegration was measured adjacent to the Stanmore $\AA$ implants when compared with the GMRS $\AA$ and Repiphysis $\AA$ implants ( $p<0.0001$ in both cases). Significantly decreased cortical loss was identified in the Stanmore ${ }^{\circledR}$ group $(p=0.005$, GMRS $\circledast$ and $p<0.0001$, Repiphysis $\AA)$ and at 3-years, the progression of radiolucent lines was reduced when compared with the GMRS $\AA$ and Repiphysis $\AA$ implants $(p=0.012$ and 0.026 respectively).

\section{Conclusions}

Implants designed to augment osseointegration at the bone-implant shoulder may be critical in reducing short- to mid-term aseptic loosening in this vulnerable DFR patient group. Further longer-term studies are required to confirm these preliminary findings.

\section{Introduction}

Osteosarcoma is a primary malignancy of bone that most commonly impacts the distal femur, predominantly affecting those between the ages of 10 and 14 and those over the age of 65 years [1]. Neoadjuvant chemotherapy combined with tumor resection is accepted as the treatment of choice [2]. Replacement of the distal femur with a mega endoprosthesis after wide tumor resection offers the benefits of same-day weight bearing, faster rehabilitation, and early walking [3]. Long-term 10- and 15year survival rates following total knee replacement surgery are reported to range between $90.9-95.4 \%$ [4]. In contrast, Haijie et al. [5] recently reported that the mean 5-, 10-, 15- and 20-year implant survival rate 
of a distal femoral replacement (DFR) in adults was $78.3 \%, 70.1 \%, 61.6 \%$ and $38.3 \%$ respectively. The identifiable risk factors are younger age, an increased level of bone resection and increased time of follow-up, which places the pediatric population at particularly high risk [6]. Implant infection and aseptic loosening (ASL) of the intramedullary stem remain the recognized major causes of failure [7-9]. At the tissue level, ASL begins with localized cortical bone loss at the bone-shoulder implant junction [10]. With time, this cortical bone loss is accompanied by the progression of radiolucent lines between the cementbone interface adjacent to the intramedullary stem, eventually leading to ASL and implant failure. Concerns for successful long-term fixation stimulated modifications in implant materials and design and to date several are in use, each with varying features targeted to reduce bone loss and ASL. Modern designs incorporate a bone ingrowth collar at the bone-implant shoulder with the goal of encouraging extracortical bone-implant osseointegration. This is reported to reduce disadvantageous high stresses within the stem fixation and protect the implant against ASL and surgical revision [11-14]. Typically, bone does not directly adhere to a polished metal surface and varying types of ingrowth surfaces including fibermetal, porous metal coatings and more recently a hydroxyapatite (HA) coating have been assessed clinically [10,14-19]. Other prosthetic advancements include Biomet's Compress Compliant Pre-Stress (CPS ${ }^{\circledR}$ ) technology (ZimmerBiomet Inc, Warsaw, IN, USA), designed to apply beneficial dynamic compressive loads to the bone cortex at the shoulder. This may eliminate ASL and is secured to bone without reliance on an intramedullary stem [20-24].

The aim of this study was to retrospectively review the clinical outcome of primary DFRs in young patients (<20-years) in the short- and mid-term. All patients had received either a Stanmore ${ }^{\circledR}$ implant, a CPS ${ }^{\circledR}$ implant, the Stryker Global Modular Replacement System (GMRS ${ }^{\circledR}$, Stryker, Mahwah NJ, USA) or a Repiphysis ${ }^{\circledR}$ implant (Repiphysis Limb Salvage System; Wright Medical Technology, Arlington, TN, USA). This study also aimed to evaluate the effect of an implant shoulder composed of a HA coated grooved ingrowth collar (Stanmore $\AA$ ), a plasma sprayed porous titanium coating (GMRS $\AA$ ) or a polished metal surface (Repiphysis $\mathbb{B}$ ) on the level of osseointegration and incidence and progression of radiolucent lines adjacent to the intramedullary stem fixation. Our hypothesis was that increased extracortical osseointegration at the bone-implant shoulder will improve stress transfer adjacent to the stem, as evidenced by reduced cortical bone loss, radiolucent line progression and implant failure.

\section{Methods}

Between 2000 and 2020, 30 patients underwent primary DFR limb salvage surgery within the Nemours Children's Health system at hospitals based in Orlando, Pensacola and Jacksonville in Florida, and at the Nemours/Alfred I. duPont Hospital for Children in Wilmington, Delaware, United States. This study received ethical board approval from the Nemours Office of Human Subjects Protection (IRB\# 1351573). Our study was retrospective and as such, written informed consent was not required. Data was retrieved from the EPIC electronic medical record system. Surgery was performed by one of six orthopaedic surgeons and all patients were treated following a biopsy-proven diagnosis of high-grade osteosarcoma. Patients who received a DFR for the reconstruction of a metastatic lesion or in a revision procedure were excluded. One patient was excluded as the DFR was a revision, leaving 29 patients (Figs. 1 and 2). 
All patients received neoadjuvant and adjuvant multidrug combination chemotherapy in accordance with the Children's Oncology Group AOST 0331 study (Table 1). Patients received cisplatin, doxorubicin and methotrexate (MAP) and during DFR surgery, chemotherapeutic efficacy was determined according to changes in tumor size. Those patients with no or limited tumor regression at the time of surgery were categorized as non-responders and their chemotherapeutic treatment was modified accordingly. The implant design variables are presented in Table 2 and implant removal and clinical complications were assessed in accordance with the Henderson Classification system of endoprosthetic failure [25] (Table 3).

\section{Radiographic Analysis}

Radiographic analysis was performed by examining both antero-posterior (AP) and medio-lateral (ML) radiographs taken of each patient throughout the length of the follow-up period. In total, 99 radiographs were analyzed with a mean of 6 (range, 1-18) radiographs per patient. The number of radiographs available varied according to length of follow up, frequency of follow up imaging, and availability of radiographs. Analysis included determination of, (1) extracortical bone growth over the bone-implant junction, (2) osseointegration at the bone-implant shoulder, (3) cortical bone loss at the shoulder of the

prosthesis and, (4) radiolucent line (RL) progression adjacent to the cemented stem fixation (Figs. 3a and b). As the CPS $\circledast$ device does not feature a cemented stem, these implants were not included in the radiographic analysis. Radiographic images taken immediately post-operation were used to measure the most proximal point on the greater trochanter down to the most distal point of the patellar surface, and \%bone resection was calculated.

\section{Extracortical Bone Formation and Osseointegration}

The implant shoulder was divided into four quadrants (antero-posterior and medio-lateral) and the presence of extracortical bone growth scored as 0 where no extracortical growth was observed, and 1 when bone growth was observed in any 1 of the 4 quadrants. Similarly, evidence of radiographic osseointegration was also scored, where the presence of a radiolucent line separating the bony pedicle from the implant surface in any 1 of the 4 quadrants deemed the collar non-osseointegrated (score of 0 ). When radiographic osseointegration was present, the collar was given a score of 1 .

\section{Cortical Bone Loss}

Cortical bone loss was defined as the clear separation of bone $(>1 \mathrm{~mm})$ from the shoulder of the implant. If a gap of $>1 \mathrm{~mm}$ was observed, a score of 1 was given, while no cortical bone loss at the interface was given a score of 0 .

\section{Radiolucent Line Score}

The progression of a radiolucent line at the bone-cement interface adjacent to the stem was quantified from serial radiographs. Each AP and ML radiograph were divided into 12 equidistant zones (Fig. 3c) [10]. A score of zero indicated that no radiolucent lines were observed. A score of 1 was given when a radiolucent line was observed in 1 zone and a maximal score of 24 indicated a loose stem fixation 
surrounded by radiolucent lines along the entire length, in both AP and ML planes. The progression of these lines was measured over the follow-up period.

\section{Statistics}

Implant survival was determined using a Kaplan-Meier analysis starting from the date of the original surgery with an end point of failure for any reason. Endoprosthetic failure was defined as the need for complete revision of the cemented component and conversion to a different prosthesis. Removal of the implant due to disease progression and amputation was not included as a cause of implant failure. Replacement of mechanically worn parts (e.g., bushings for the hinge knee replacement) were counted as complications and not as implant failures. The parameters of implant type, sex, age, \%bone resection, implant lengthening, and length of follow-up were correlated with implant complications and the need for revision surgery. Differences in the prevalence of complications were assessed using the chi-square test. A Mann Whitney $U$ test was used to compare radiographic scores between groups. All analyses were performed using IBM SPSS software (v25.0, SPSS, Illinois, USA) where $p$ values $<0.05$ were considered significant.

\section{Results}

\section{Patient Survival}

A total of 7 patients died (75.9\% survival) (Table 4) where 3 of the 7 deaths showed poor response to chemotherapy at the time of surgical tumor resection. Femoral tumor recurrence occurred in 3 patients $(10.3 \%)$ and an amputation was performed in 2 patients at a mean follow up of $1.64 \pm 0.95 \mathrm{y}(0.97$ and 2.31y). The third patient was converted to a total femoral implant at 10-years follow up.

\section{Implant Removal}

Kaplan-Meier analysis showed an implant survivorship of $100.0 \%$ in the Stanmore ${ }^{\circledR}$ group, $90.0 \%$ in the GMRS ${ }^{\circledR}, 81.8 \%$ in the CPS ${ }^{\circledR}$, and $33.3 \%$ in the Repiphysis ${ }^{\circledR}$ group over the follow up period (Fig. 4). When all implant types were combined, overall implant survival was $82.8 \%$. A total of 5 implants $(17.2 \%)$ were revised (Fig. 5 and Table 5). A trend of increased implant revision in male patients was observed (71.4\%, $p=0.058$ ). The use of the extendable Stanmore ${ }^{\circledR}$ prosthesis was favored in the younger age group ( $p=$ $0.025)$ whereas the GMRS $\AA$ implant was most commonly used in older patients $(p=0.043)$. No significant differences in the total dose of MAP given per patient were found when compared between each of the implant groups (Table 6).

\section{Complications, lengthening and \%bone resection}

Sixteen of 29 patients $(55.2 \%)$ were re-admitted during the follow up period and clinical complications were identified in $83.3 \%$ of patients. A trend was seen where the incidence of complications increased as the length of follow up increased $(p=0.057)$. All 5 of the Stanmore ${ }^{\circledR}$ prostheses were lengthened in addition to 2 Repiphysis $\AA$ and 1 CPS $\circledast$ implant. The mean number of lengthening sessions was $10.9 \pm$ 
3.1 (range, 4-28) and the mean lengthening amount was $56.2 \pm 20.3 \mathrm{~mm}$ (range, $17-175 \mathrm{~mm}$ ). Percentage bone resection varied between groups (Table 7).

\section{Radiographic Findings}

A significantly increased incidence of extracortical bone growth was measured adjacent to the Stanmore $\circledast$ implants (mean score, $0.83 \pm 0.06)$ when compared with the GMRS ${ }^{8}(0.44 \pm 0.08, p<0.0001)$ and Repiphysis ${ }^{\circledR}(0.31 \pm 0.12, p<0.0001)$ implants (Fig. 6). Thirty-one of the 41 radiographs analyzed in the Stanmore $\circledast$ group demonstrated osseointegration (75.6\%), and 11 of the 39 radiographs $(29.2 \%)$ showed evidence of osseointegration at the collar region in the GMRS ${ }^{\circledR}$ group, while none of the 19 radiographs had osseointegrated in the Repiphysis ${ }^{\circledR}$ group (Fig. 7). Significantly decreased cortical bone loss was measured in the Stanmore ${ }^{\circledR}$ group (mean, $\left.0.10 \pm 0.05\right)$ when compared with the GMRS $\circledast(0.36$ $\pm 0.08, p=0.005)$ and Repiphysis $\AA$ implants $(0.69 \pm 0.12, p<0.0001$; Fig. 8$)$. The progression of radiolucent line formation progressed most rapidly in the Repiphysis ${ }^{\circledR}$ group (Fig. 9). Significant correlations between implant failure and increased cortical loss $(p=0.017)$ and increased radiolucent line score and cortical loss $(p=0.049)$ were found. No other significant correlations were found.

\section{Qualitative Analysis: CPS $\circledast$ Implant}

Radiographic analysis of all patients with a CPS $\odot$ implant showed stable bone-implant fixation with no evidence of aseptic failure. Bone hypertrophy at the implant shoulder was observed in all patients in the years following surgery, with hypertrophy also seen associated with the pins in some patients (Fig. 10).

\section{Discussion}

Bone tumors in children are rare and prior to the use of effective chemotherapy, overall patient survival rates were reported to be $15-20 \%$ at 2-years following surgical resection and/or radiotherapy [26, 27]. This study demonstrated a patient survival rate of $75.9 \%$ over a mean follow up of 4.25 years. Although patient survival is highly dependent on the stage of osteosarcoma at diagnosis, our result is similar to other recent studies who report contemporary 5 -year patient survival rates ranging between $60-78 \%$ in pediatric patients following limb-salvage and MAP treatment [28-31]. Thus, the challenges of DFR longevity remains a priority as overall survival and activity levels continues to improve however, surgery is challenging in growing children and problems can result in loss of joint function, high-level amputation, and systemic sequelae for the patient [32]. Aseptic loosening in young and physically active patients who place high demands on their prosthesis is a major concern [33]. A study by Unwin et al. [6] reported a $67.4 \%$ probability of a Stanmore ${ }^{\circledR}$ DFR survival at 10 years with a significantly higher risk of ASL (13.6\%) in patients $<20$-years of age. Further, this study also identified that patients $<20$-years of age and with $>$ $60 \%$ of bone resection, having the poorest prognosis. In this study, an encouraging overall implant survival rate of $82.8 \%$ was found and the incidence of ASL that required revision was $10.3 \%$. No correlation between \%bone resection and implant failure was seen although mean levels were less than $60 \%$. To determine load distribution within the intramedullary fixation in adults, a clinical study by Taylor et al. [34] added strain gauges and telemetric instrumentation to a massive implant. At 100 weeks post- 
surgery, $60 \%$ of the applied load was directed through the cemented stem fixation when compared with $25 \%$ in the more immediate post-op period. These findings suggested a progressive mechanical cause of ASL and led to the concept that osseointegration at the shoulder offered more beneficial load distributions. As such, the Stanmore $\AA$ and CPS $\AA$ implants were designed to maximize osseous growth at the shoulder, and in this study, none of these implants failed due to ASL. Hydroxyapatite is classified as a bioactive, osseoconductive and osseoinductive material and bone is able to chemically bond with it providing increased interfacial and mechanical coupling, to superior levels when compared with a polished titanium implant surface $[35,36]$. Our results showed significantly increased extracortical bone growth and osseointegration to the HA collar in the Stanmore ${ }^{\circledR}$ group when compared with both the GMRS $\AA$ and Repiphysis $\AA$ implants. Significantly reduced cortical loss and the progression of radiolucent lines was also evident in Stanmore-given patients over the follow up period. These results are similar to other studies that investigated osseointegration and ASL $[10,13,14]$. This study demonstrated poor performance of the Repiphysis $\AA$ design where 2 of the 3 implants inserted were revised. Results are similar to other studies that report high rates of ASL as well as mechanical failure in young patients [3741]. Two recent studies also reported a $100 \%$ implant survival rate of the Stanmore ${ }^{\circledR}$ implant in pediatric patients and both demonstrated overall poor survival (79.2\% at 2-years and $21 \%$ at 5 -years) of the PhenixRephiphysis ${ }^{\circledR}$ implant at a mean follow-up of 6.2 years [42] and $32 \%$ survival at 6 -years [43].

Infection of massive endoprostheses ranges between $8-40 \%[44,45]$ with CPS $\circledast$ implant infection reported as $14 \%$ over a 20 -year follow-up [46]. In this study, none of the DFR implants were revised due to infection and 3 patients were successfully treated for implant-associated infection. Two of these 3 patients had received a CPS $\circledast$ implant, however this group of patients also experienced significantly higher \%bone resection levels and the increased tissue exposed during surgery may account for the infections observed. Two CPS $\mathbb{B}$ implants failed due to fracture of the titanium traction bar. In both patients the implants appeared radiographically well fixed. Traction bar fracture has been reported in the same location in other studies $[47,48]$ however, the reason for fracture remains unclear. Nevertheless, our results indicate that the CPS $\AA$ implant continues to be a reliable option for distal femoral limb salvage surgery and the absence of ASL is encouraging. Finally, multidrug chemotherapy impairs bone growth and causes early radiological signs of loosening in DFRs [49]. No significant differences were found when the total dose and length of treatment was compared between implant groups.

Our study had several limitations. First, osteosarcoma is rare and as such, the study is limited by its small sample size as well as loss of follow-up as patients transitioned out of the hospital system and into adult care. Furthermore, the cohort of patients presented individual differences in their activity levels, which would impact prosthetic survival. Because this study was a retrospective study, both AP and ML radiographs were not always available for review and this reduced the number of patients followed-up beyond 6-years post-operatively.

In conclusion, chemotherapy and limb-salvage surgery yield good oncologic outcomes. Results from this study suggest that implant designs modified to augment osseointegration at the bone-implant shoulder may be critical in reducing the initiation and development of ASL in this vulnerable patient group. While 
the limitations of this study do not allow us to conclude that extracortical bone growth and osseointegration is directly responsible for a lower incidence of ASL, our results do confirm the ability of the HA collar to increase radiographic bone-implant contact at the implant shoulder. Further studies that involve a larger cohort over a longer follow-up are needed to confirm these preliminary findings.

\section{Declarations}

\section{Acknowledgments and Conflicts of Interests}

This research received no specific grant from any funding agency in the public, commercial or not-forprofit sectors and none of the authors have any conflicts of interest to disclose.

\section{References}

1. Ottaviani G, Jaffe N. The epidemiology of osteosarcoma. Cancer Treat Res. 2009;152:3-13. doi: 10.1007/978-1-4419-0284-9_1.

2. Isakoff MS, Bielack SS, Meltzer P, Gorlick R. Osteosarcoma: Current Treatment and a Collaborative Pathway to Success. J Clin Oncol. 2015;33(27):3029-3035. doi: 10.1200/jco.2014.59.4895.

3. Pala E, Trovarelli G, Calabrò T, Angelini A, Abati CN, Ruggieri P. Survival of modern knee tumor megaprostheses: failures, functional results, and a comparative statistical analysis. Clin Orthop Relat Res. 2015;473(3):891-899. doi: 10.1007/s11999-014-3699-2.

4. Kim, GW., Jin, Q.H., Lim, JH. et al. No difference of survival between cruciate retaining and substitution designs in high flexion total knee arthroplasty. Sci Rep 2021;11, 6537. https://doi.org/10.1038/s41598-021-85892-1

5. Haijie L, Dasen L, Tao J, Yi Y, Xiaodong T, Wei G. Implant Survival and Complication Profiles of Endoprostheses for Treating Tumor Around the Knee in Adults: A Systematic Review of the Literature Over the Past 30 Years. J Arthroplasty. 2018 Apr;33(4):1275-1287.e3. doi:

10.1016/j.arth.2017.10.051. Epub 2017 Nov 7. PMID: 29191444.

6. Unwin PS, Cannon SR, Grimer RJ, Kemp HB, Sneath RS, Walker PS. Aseptic loosening in cemented custom-made prosthetic replacements for bone tumours of the lower limb. J Bone. Joint Surg Br. 1996;78:5-13.

7. Batta V, Coathup MJ, Parratt MT, et al. Uncemented, custom-made, hydroxyapatite-coated collared distal femoral endoprostheses: up to 18 years' follow-up. Bone Joint J. 2014;96-b(2):263-269. doi: 10.1302/0301-620x.96b2.32091.

8. Turcotte RE, Stavropoulos NA, Toreson J, Alsultan M. Radiographic assessment of distal femur cemented stems in tumor endoprostheses. Eur J Orthop Surg Traumatol. 2017;27(6):821-827. doi: 10.1007/s00590-017-1965-1.

9. Sharma S, Turcotte RE, Isler MH, Wong C. Experience with cemented large segment endoprostheses for tumors. Clin Orthop Relat Res. 2007;459:54-59. doi: 10.1097/BLO.0b013e3180514c8e. 
10. Coathup MJ, Sanghrajka A, Aston WJ, et al. Hydroxyapatite-coated collars reduce radiolucent line progression in cemented distal femoral bone tumor implants. Clin Orthop Relat Res. 2015;473(4):1505-1514. doi: 10.1007/s11999-014-4116-6.

11. Chao EY, Sim FH. Composite fixation of segmental bone/joint defect replacement (SDR) prostheses: biological and biomechanical justifications. Chir Organi Mov. 1990;75(1 suppl):171-173.

12. Taylor SJ, Perry JS, Meswania JM, Donaldson N, Walker PS, Cannon SR. Telemetry of forces from proximal femoral replacements and relevance to fixation. J Biomech. 1997;30:225-234.

13. Fromme P, Blunn GW, Aston WJ, Abdoola T, Koris J, Coathup MJ. The effect of bone growth onto massive prostheses collars in protecting the implant from fracture. Med Eng Phys. 2017 Mar;41:1925. doi: 10.1016/j.medengphy.2016.12.007.

14. Coathup MJ, Batta V, Pollock RC, et al. Long-term survival of cemented distal femoral endoprostheses with a hydroxyapatite-coated collar: a histological study and a radiographic followup. J Bone Joint Surg Am. 2013;95(17):1569-1575. doi: 10.2106/jbjs.L.00362.

15. Heck DA, Chao EY, Sim FH, Pritchard DJ, Shives TC. Titanium fibermetal segmental replacement prostheses. A radiographic analysis and review of current status. Clin Orthop Relat Res. 1986; (204):266-85.

16. Kuo KN, Gitelis S, Sim FH, Pritchard D, Chao E, Rostoker W, Galante JO, McDonald P. Segmental replacement of long bones using titanium fiber metal composite following tumor resection. Clin Orthop Relat Res. 1983;(176):108-14.

17. Heck DA, Nakajima I, Kelly PJ, Chao EY. The effect of load alteration on the biological and biomechanical performance of a titanium fiber-metal segmental prosthesis. J Bone Joint Surg Am. 1986;68(1):118-26.

18. Ward WG, Johnston KS, Dorey FJ, Eckardt JJ. Extramedullary porous coating to prevent diaphyseal osteolysis and radiolucent lines around proximal tibial replacements. A preliminary report. J Bone Joint Surg Am. 1993;75(7): 976-87.

19. Okada Y, Suka T, Sim FH, Gorski JP, Chao EYS. Comparison of replacement prostheses for segmental defects of bone. Different porous coatings for extracortical fixation. J Bone Joint Surg Am. 1988;70(2):160-72.

20. Pedtke AC, Wustrack RL, Fang AS, Grimer RJ, O'Donnell RJ. Aseptic failure: how does the Compress $(\circledR)$ implant compare to cemented stems?. Clin Orthop Relat Res. 2012;470(3):735-742. doi:10.1007/s11999-011-2159-5

21. Bhangu AA, Kramer MJ, Grimer RJ, O'Donnell RJ. Early distal femoral endoprosthetic survival: cemented stems versus the Compress implant. Int Orthop. 2006;30(6):465-472. doi:10.1007/s00264-006-0186-8

22. Zimel MN, Farfalli GL, Zindman AM, et al. Revision Distal Femoral Arthroplasty With the Compress $(\circledR)$ Prosthesis Has a Low Rate of Mechanical Failure at 10 Years. Clin Orthop Relat Res. 2016;474(2):528-536. doi: 10.1007/s11999-015-4552-y. 
23. Farfalli GL, Boland PJ, Morris CD, Athanasian EA, Healey JH. Early equivalence of uncemented pressfit and Compress femoral fixation. Clin Orthop Relat Res. 2009;467(11):2792-2799. doi: 10.1007/s11999-009-0912-9.

24. Healey JH, Morris CD, Athanasian EA, Boland PJ. Compress knee arthroplasty has 80\% 10-year survivorship and novel forms of bone failure. Clin Orthop Relat Res. 2013;471(3):774-783. doi: 10.1007/s11999-012-2635-6.

25. Henderson ER, O'Connor MI, Ruggieri P, Windhager R, Funovics PT, Gibbons CL, Guo W, Hornicek FJ, Temple HT, Letson GD. Classification of failure of limb salvage after reconstructive surgery for bone tumours: a modified system Including biological and expandable reconstructions. Bone Joint J. 2014 Nov;96-B(11):1436-40. doi: 10.1302/0301-620X.96B11.34747. PMID: 25371453.

26. Bielack SS, Bernstein ML. Cancer in Children: Clinical Management. 5th ed. New York: Oxford University Press; 2005. Osteosarcoma.

27. Carrle D, Bielack SS. Current strategies of chemotherapy in osteosarcoma. Int Orthop. 2006 Dec; $30(6): 445-51$.

28. Jeys LM, Kulkarni A, Grimer RJ, Carter SR, Tillman RM, Abudu A. Endoprosthetic reconstruction for the treatment of musculoskeletal tumors of the appendicular skeleton and pelvis. J Bone Joint Surg Am. 2008;90(6):1265-1271. doi: 10.2106/jbjs.F.01324.

29. Nagarajan R, Kamruzzaman A, Ness KK, Marchese VG, Sklar C, Mertens A, Yasui Y, Robison LL, Marina N. Twenty years of follow-up of survivors of childhood osteosarcoma: a report from the Childhood Cancer Survivor Study. Cancer. 2011 Feb 1; 117(3):625 - 34.

30. Abou Ali B, Salman M, Ghanem KM, Boulos F, Haidar R, Saghieh S, Akel S, Muwakkit SA, El-Solh H, Saab R, Tamim H, Abboud MR. Clinical Prognostic Factors and Outcome in Pediatric Osteosarcoma: Effect of Delay in Local Control and Degree of Necrosis in a Multidisciplinary Setting in Lebanon. J Glob Oncol. 2019 Apr;5:1-8. doi: 10.1200/JG0.17.00241. PMID: 30946633; PMCID: PMC6528739.

31. Isakoff MS, Bielack SS, Meltzer P, Gorlick R. Osteosarcoma: Current Treatment and a Collaborative Pathway to Success. J Clin Oncol. 2015 Sep 20; 33(27):3029-35.

32. Ottaviani G, Robert RS, Huh WW, Jaffe N. Functional, psychosocial and professional outcomes in long-term survivors of lower-extremity osteosarcomas: amputation versus limb salvage. Cancer Treat Res. 2009; 1520:421 - 36.

33. Griffin AM, Parsons JA, Davis AM, Bell RS, Wunder JS. Uncemented tumor endoprostheses at the knee: root causes of failure. Clin Orthop Relat Res 2005;438:71-79.

34. Taylor S, Perry J, Adler J, Unwin PS, Walker PS. The telemetry of forces in vivo developed in massive orthopaedic implants: the first 18 months results from walking. In: Tan SK, ed. Limb Salvage: current trends. Singapore: ISOLS, 1993:560.

35. Geesink RGT, de Groot K, Klein CPAT. Bonding of bone to apatite-coated implants. J Bone Joint Surg 1988;70B:17-22.

36. Porter AE, Taak P, Hobbs LW, Coathup MJ, Blunn GW, Spector M. Bone bonding to hydroxyapatite and titanium surfaces on femoral stems retrieved from human subjects at autopsy. Biomaterials. 2004 
Sep;25(21):5199 - 208. doi: 10.1016/j.biomaterials.2003.12.018. PMID: 15109844.

37. Wodajo FM. CORR Insights(®): Are Complications Associated With the Repiphysis(®) Expandable Distal Femoral Prosthesis Acceptable for Its Continued Use?. Clin Orthop Relat Res. 2015;473(9):3014-3016. doi:10.1007/s11999-015-4407-6

38. Beebe KS, Uglialoro AD, Patel N, Benevenia J, Patterson FR. Mechanical failure of the Repiphysis expandable prosthesis: a case report. J Bone Joint Surg Am. 2010 May; 92(5):1250-3.

39. Maheshwari AV, Bergin PF, Henshaw RM. Modes of failure of custom expandable repiphysis prostheses: a report of three cases. J Bone Joint Surg Am. 2011 Jul 6; 93(13):e72.

40. Cipriano CA, Gruzinova IS, Frank RM, Gitelis S, Virkus WW. Frequent complications and severe bone loss associated with the repiphysis expandable distal femoral prosthesis. Clin Orthop Relat Res. 2015 Mar; 473(3):831-8.

41. Staals EL, Colangeli M, Ali N, Casanova JM, Donati DM, Manfrini M (2015) Are Complications Associated With the Repiphysis(®) Expandable Distal Femoral Prosthesis Acceptable for Its Continued Use? Clin Orthop 473:3003-3013.

42. Dukan, R., Mascard, E., Langlais, T. et al. Long-term outcomes of non-invasive expandable endoprostheses for primary malignant tumors around the knee in skeletally-immature patients. Arch Orthop Trauma Surg (2021). https://doi.org/10.1007/s00402-020-03712-z

43. Pala E, Trovarelli A, Angelini A, Maraldi M, Berizzi A, Ruggieri P. Megaprosthesis of the knee in tumor and revision surgery. Acta Biomed 88(2):129-138, 2017

44. Sigmund IK, Gamper J, Weber C, Holinka J, Panotopoulos J, Funovics PT, Windhager R. Efficacy of different revision procedures for infected megaprostheses in musculoskeletal tumour surgery of the lower limb. PLoS One. 2018 Jul 5;13(7):e0200304. doi: 10.1371/journal.pone.0200304. PMID: 29975769; PMCID: PMC6033467.

45. Morii T, Morioka H, Ueda T, Araki N, Hashimoto N, Kawai A, Mochizuki K, Ichimura S. Deep infection in tumor endoprosthesis around the knee: a multi-institutional study by the Japanese musculoskeletal oncology group. BMC Musculoskelet Disord. 2013 Jan 31;14:51. doi: 10.1186/1471-2474-14-51. PMID: 23369129; PMCID: PMC3599741.

46. Butte Z, Tanaka K, Andaya V, Zimel M, O’Donnell RJ, Wustrack R. Risk of endoprosthetic infection and impact of health-related quality of life in patients with osteosarcoma and giant cell tumor of bone; a retrospective case-control study. Annals of Joint. 2020;5.

https://aoj.amegroups.com/article/view/5732.

47. Tyler WK, Healey JH, Morris CD, Boland PJ, O'Donnell RJ. Compress periprosthetic fractures: interface stability and ease of revision. Clin Orthop Relat Res. 2009;467(11):2800-2806. doi:10.1007/s11999009-0946-z

48. Goulding KA, Schwartz A, Hattrup SJ, Randall RL, Lee D, Rispoli DM, Lerman DM, Beauchamp C. Use of Compressive Osseointegration Endoprostheses for Massive Bone Loss From Tumor and Failed Arthroplasty: A Viable Option in the Upper Extremity. Clin Orthop Relat Res. 2017 Jun;475(6):1702- 
1711. doi: 10.1007/s11999-017-5258-0. Epub 2017 Feb 13. Erratum in: Clin Orthop Relat Res. 2017 Jun;475(6):1752. PMID: 28194713; PMCID: PMC5406340

49. Mumith A, Coathup M, Edwards TC, Gikas P, Aston W, Blunn G. Multidrug chemotherapy causes early radiological signs of loosening in distal femoral replacements. Bone Joint Res. 2020 Jul 8;9(7):333340. doi: 10.1302/2046-3758.97.BJR-2019-0122.R1.

\section{Tables}

Tables 1-7 are available in the Supplementary Files section.

\section{Figures}

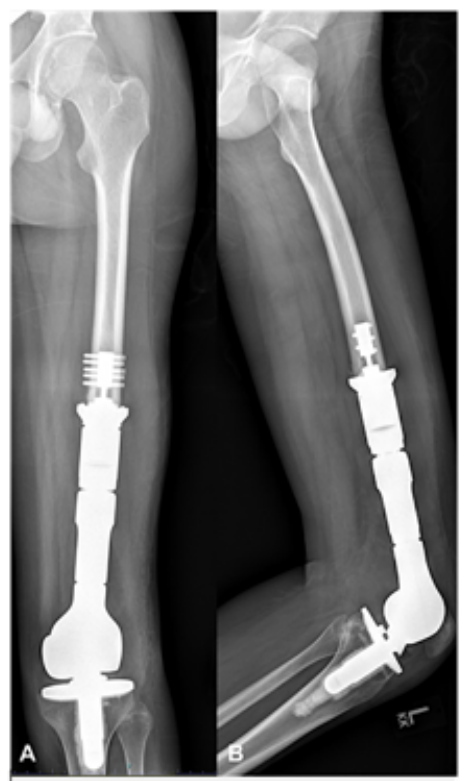

Biomet CPS $\odot$

2 months post surgery

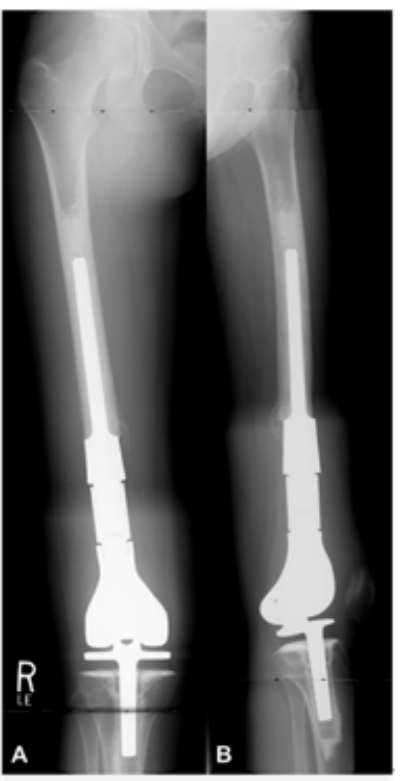

Stryker GMRS ${ }^{8}$

4 months post surgery

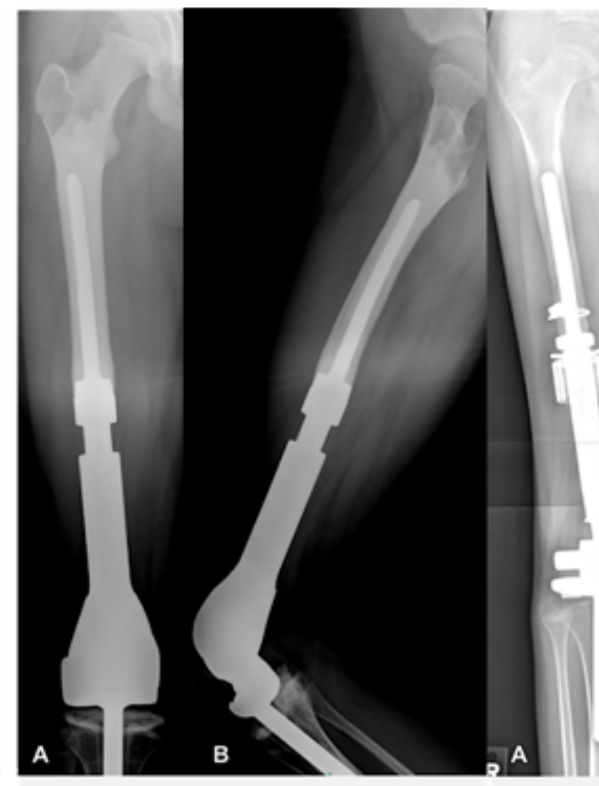

Stanmore ${ }^{8}$

2 years 10 months post surgery

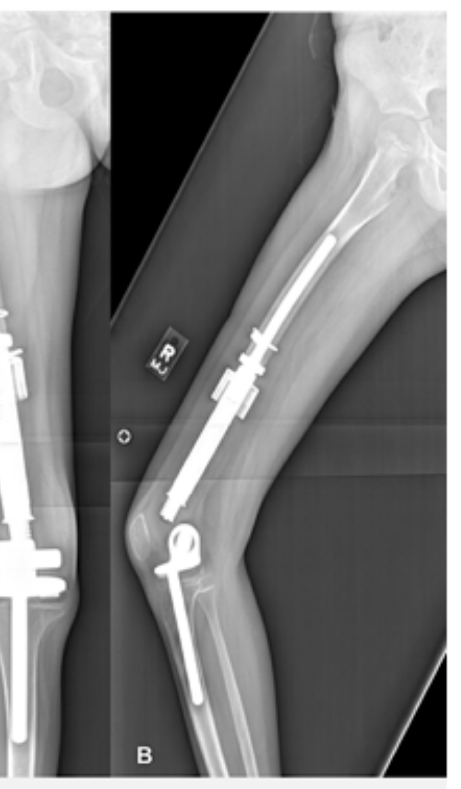

Wright Repiphysis ${ }^{\circledR}$

6 months post surgery

\section{Figure 1}

Antero-posterior $[\mathrm{A}]$ and medio-lateral $[\mathrm{B}]$ radiographs of each of the endoprosthetic designs investigated. Fifteen (51.7\%) male and 14 (48.3\%) female patients at a mean (and standard error of the mean) age of $13.09 \pm 0.56$ years (y) (range, $7.9-18.9 y$ ) were followed up for a mean of $4.25 \pm 0.55 \mathrm{y}$ (range, $0.04-$ 10.5y). Thirteen implants were inserted into the left femur and 16 into the right. Of those implants fixed using an intramedullary stem, all were cemented in place. 


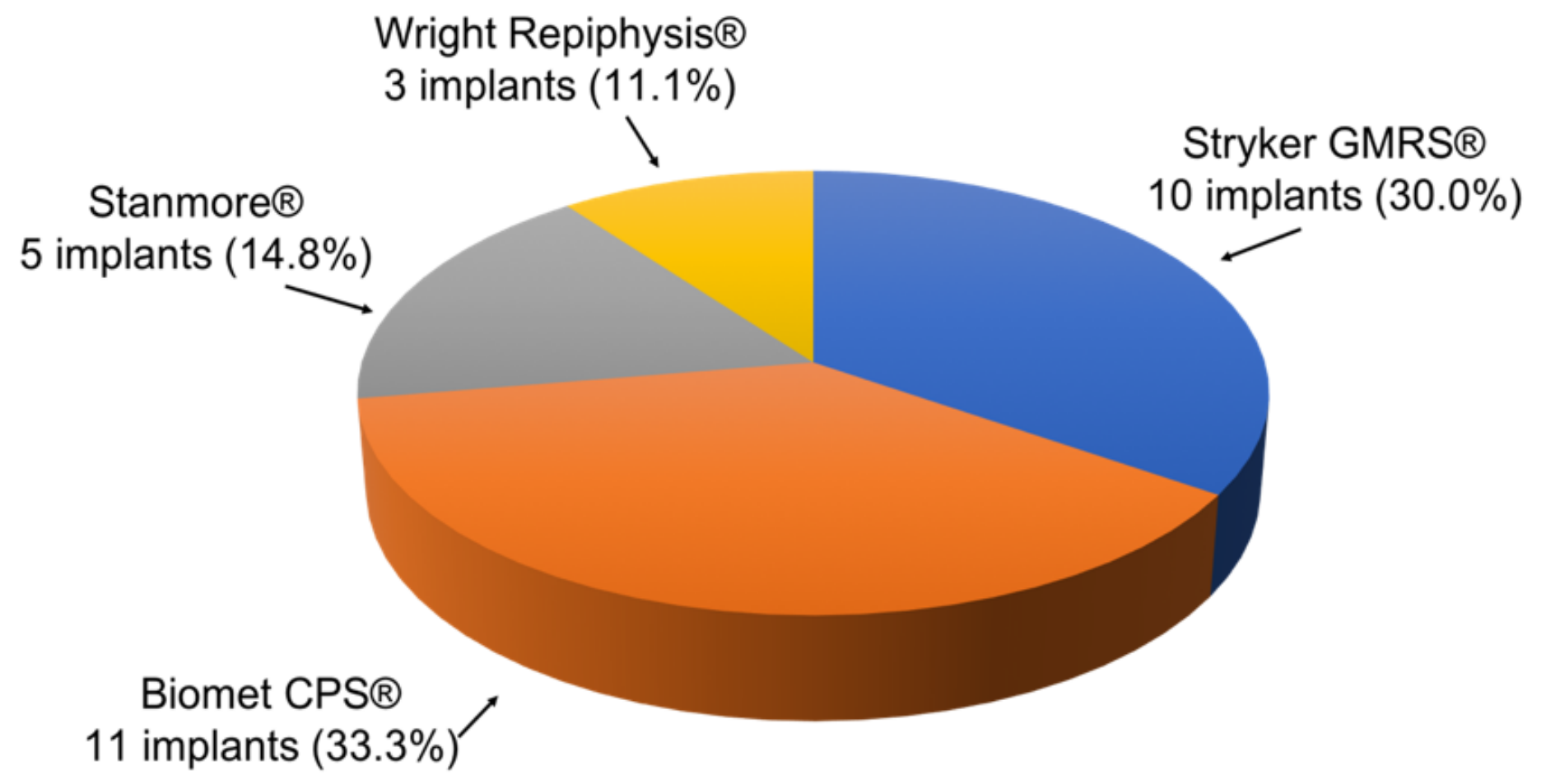

Figure 2

A pie chart showing the number and distribution of implant designs investigated. Of the endoprostheses inserted, 11 were CPS $\circledast$ implants (33.3\%, mean FU $4.07 \pm 0.88$ y (range, $0.85-8.41 \mathrm{y})$ ), 10 were GMRS $\circledast$ $(30 \%$, mean follow up $3.61 \pm 1.04 y$ (range, $0.04-10 y)$ ), 5 were of the Stanmore ${ }^{\circledR}$ design $(14.8 \%, 4.85 \pm$ $1.19 \mathrm{y}$ (range, $1.14-7.32 \mathrm{y})$ ) and 3 were Repiphysis ${ }^{\circledR}$ implants $(11.1 \%, 6.54 \pm 2.20 \mathrm{y}$ (range, $2.92-10.5 \mathrm{y})$ )
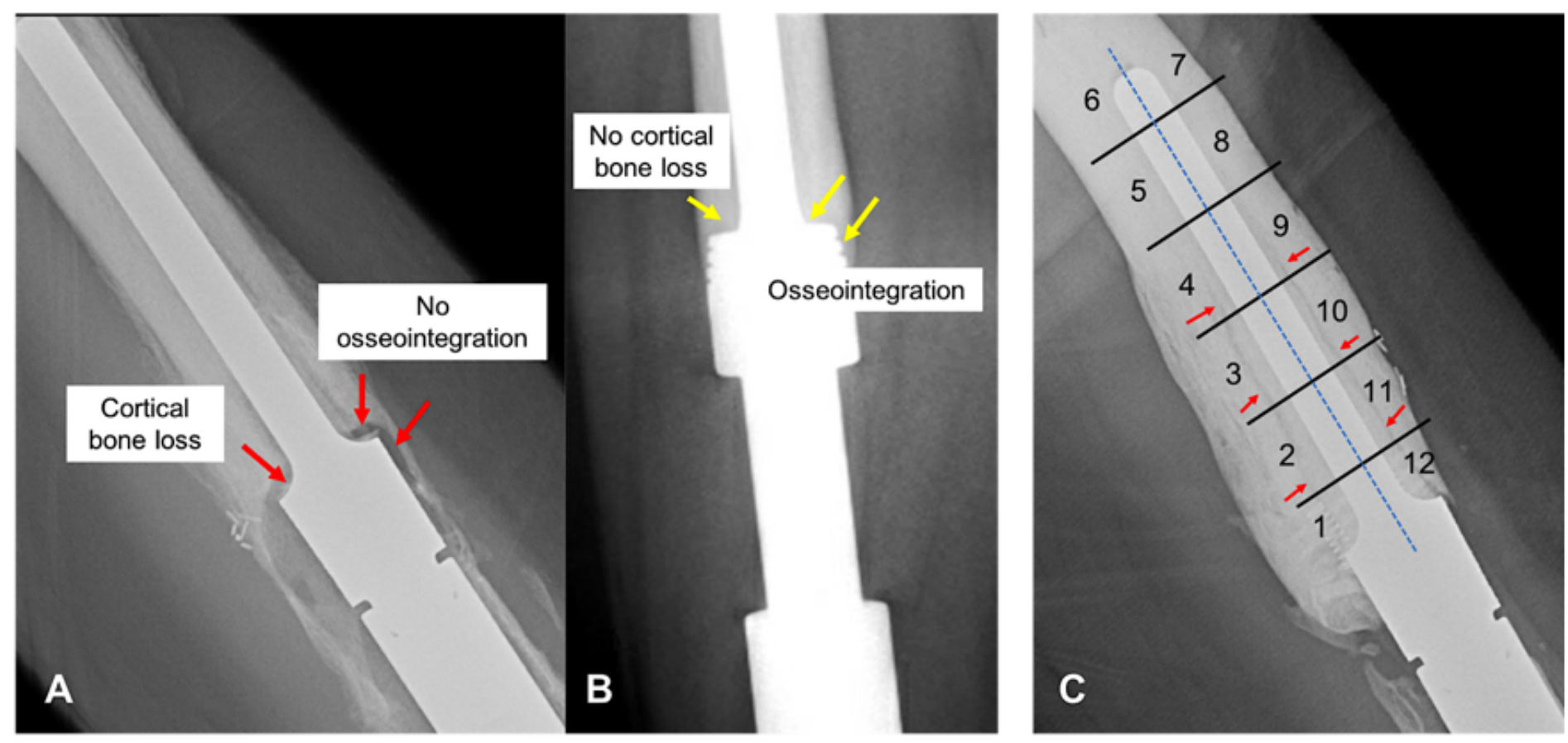


\section{Figure 3}

[A] An AP radiograph of a GMRS $\circledast$ implant showing cortical bone loss at the at the shoulder of the implant with a clear radiolucent line separating the implant surface from extracortical bone (a nonosseointegrated implant). [B] An AP radiograph of a Stanmore ${ }^{\circledR}$ implant showing bone in direct contact with the implant surface (an osseointegrated implant), with no cortical bone loss at the shoulder. [C] An AP radiograph showing the equidistant dividing lines that created six zones along the medial and 6 along the lateral aspects adjacent to the intramedullary stem. The arrows show a RL line. A maximal score of 12 indicated the presence of a radiolucent line in all 12 of these divided zones. A total score of 24 indicated additional radiolucent lines in the 12 zones measured in the corresponding ML radiograph.

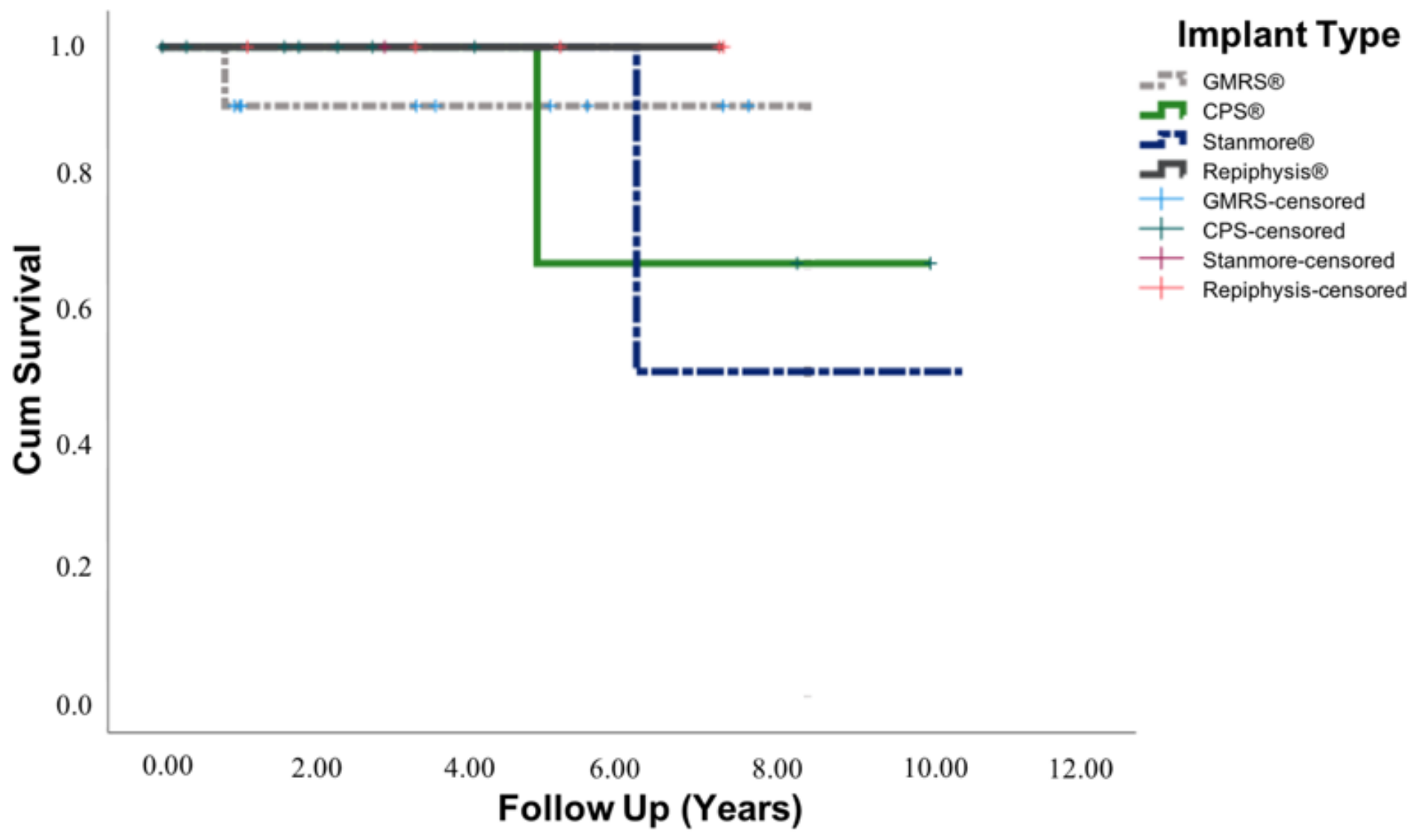

Figure 4

Kaplan-Meier survival analysis of the DFRs with respect to implant manufacturer and implant fixation failure for any reason. The percentages presented in the brackets are the survival rates of each implant design. A total of 5 implants (17.2\%) were revised; 2 CPS $\circledast$, 2 Repiphysis $\AA$ and 1 GMRS $\circledast$. Three of the 5 implants were revised due to ASL (10.3\% of 29 patients), and 2 to implant fracture (6.9\% of 29 patients) 


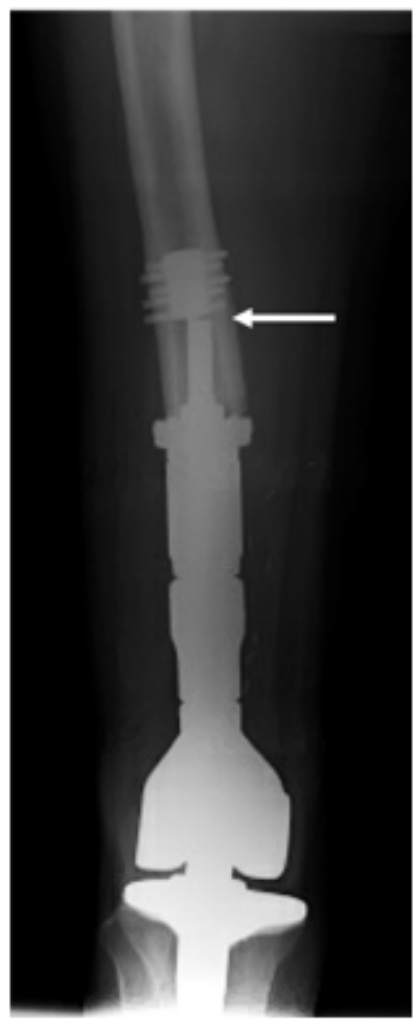

Figure 5

An AP radiograph showing fracture of a CPS $®$ implant 2 year 8 months post-surgery. The second CPS $\circledast$ implant fractured in the same region. 


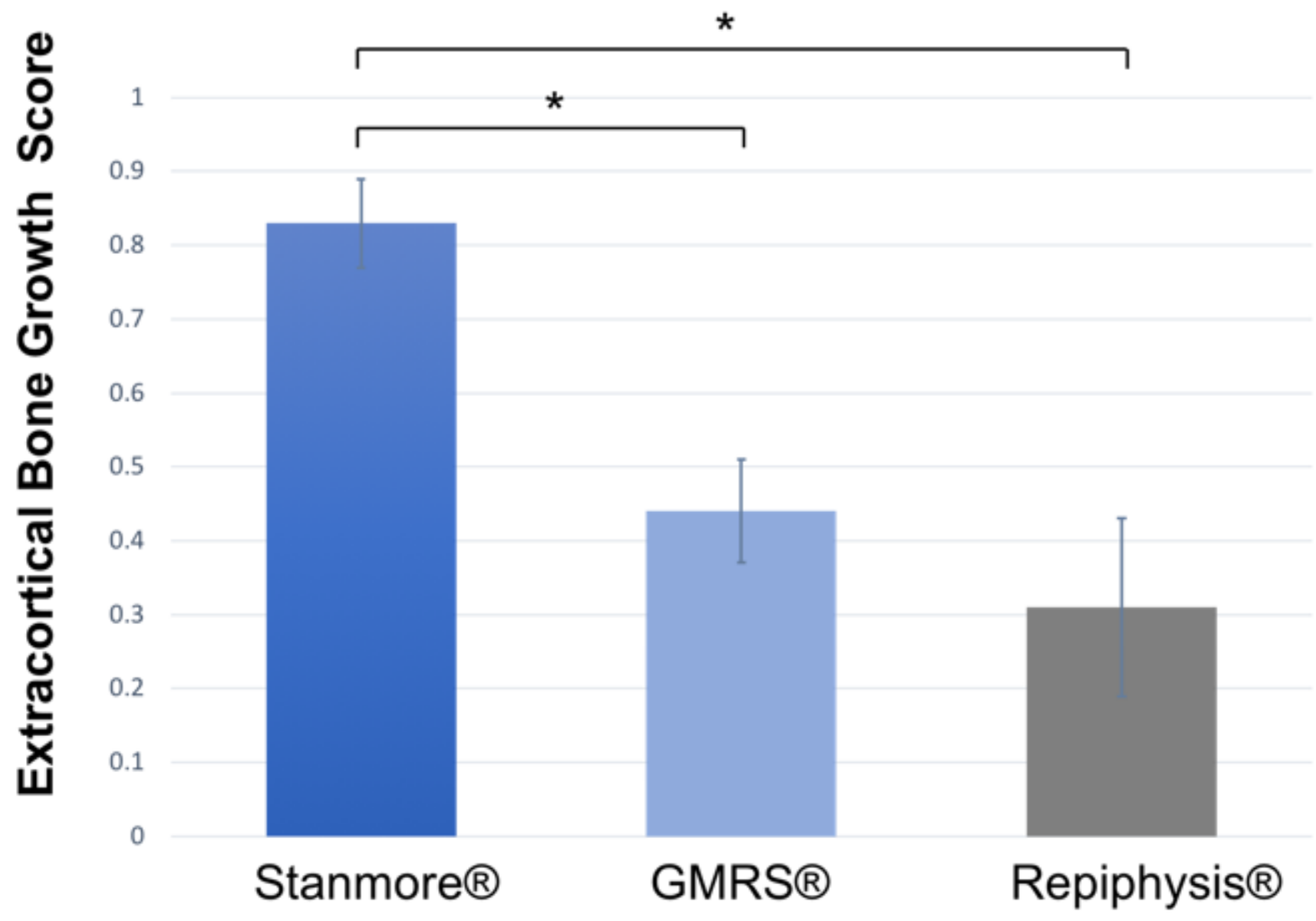

Figure 6

Extracortical bone growth score between groups. ${ }^{*} p<0.0001$ 


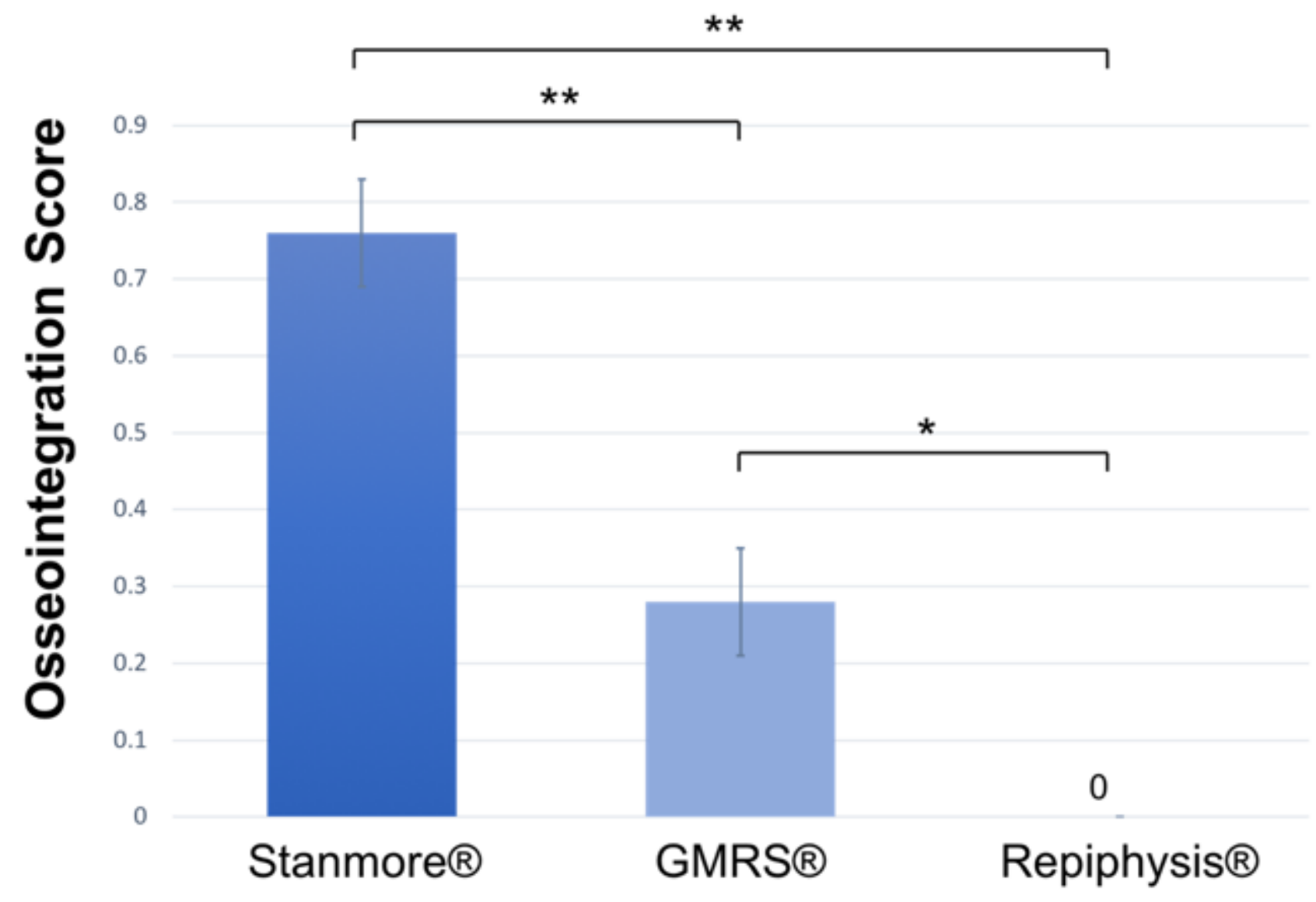

Figure 7

Osseointegration score between groups. The mean osseointegration score was significantly increased in the Stanmore ${ }^{\circledR}$ group $(0.76 \pm 0.07)$, when compared with the GMRS $\AA(0.28 \pm 0.07)$ and Repiphysis ${ }^{\circledR}$ implants. The non-osseointegrated Stanmore ${ }^{\circledR}$ implants were all in the first- or second-year following surgery and all went on to integrate in the subsequent years post-surgery. ${ }^{\star} p=0.019,{ }^{\star \star} p<0.0001$. 


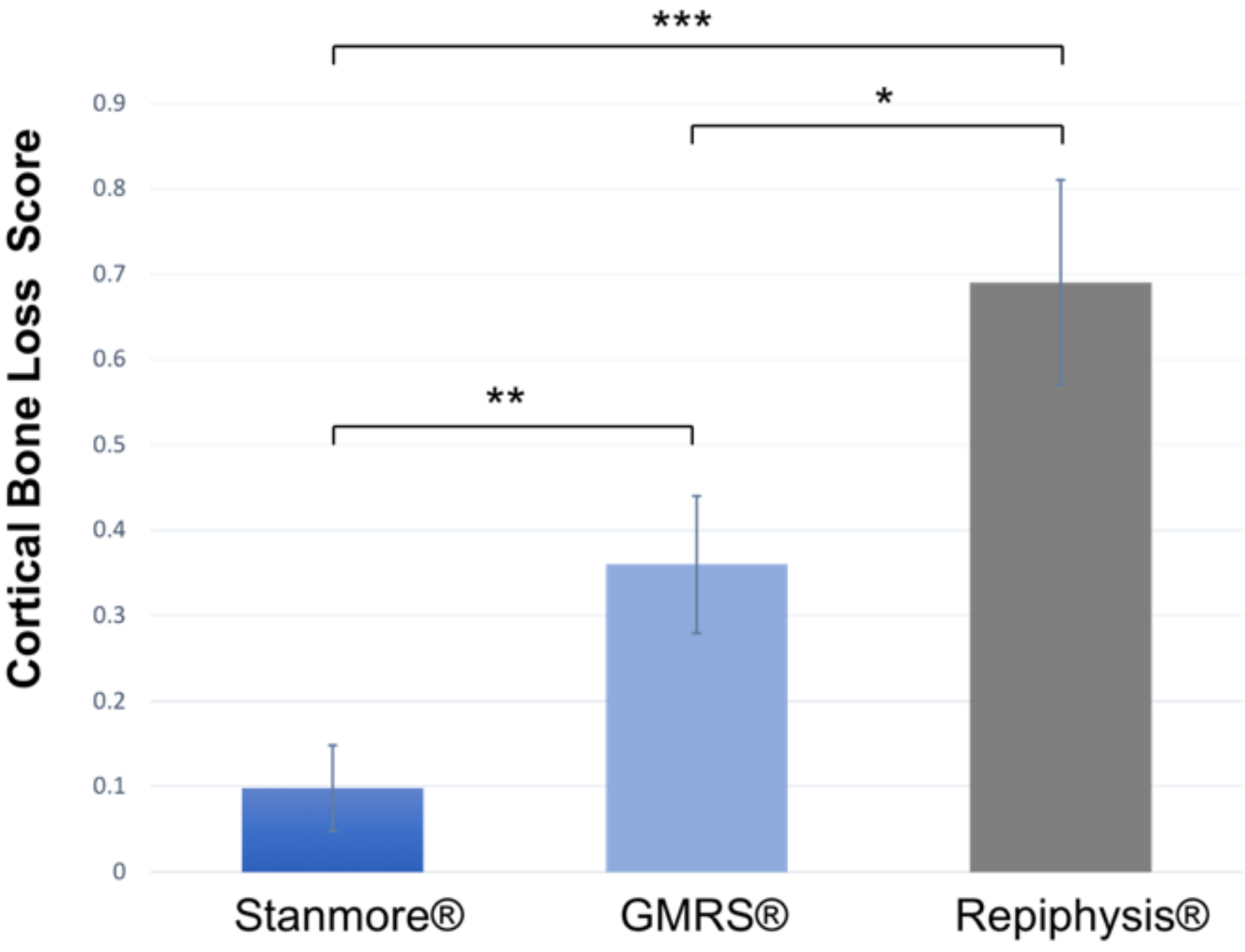

Figure 8

Cortical bone loss score between groups. $57.9 \%$ and $35.8 \%$ of the radiographs assessed in the Repiphysis ${ }^{\circledR}$ and GMRS ${ }^{\circledR}$ group respectively, demonstrated cortical bone loss at levels $>1 \mathrm{~mm}$ while $9.76 \%$ of radiographs showed signs of loss in the Stanmore ${ }^{\circledR}$ group of implants. The number of patients with both $\mathrm{AP}$ and $\mathrm{ML}$ radiographs at a follow up period $>5$ years were limited, and as such, comparisons at 6-, 7- and 8-years post-surgery were not conducted. ${ }^{\star} p=0.028,{ }^{\star \star} p=0.005,{ }^{\star \star \star} p<0.0001$ 


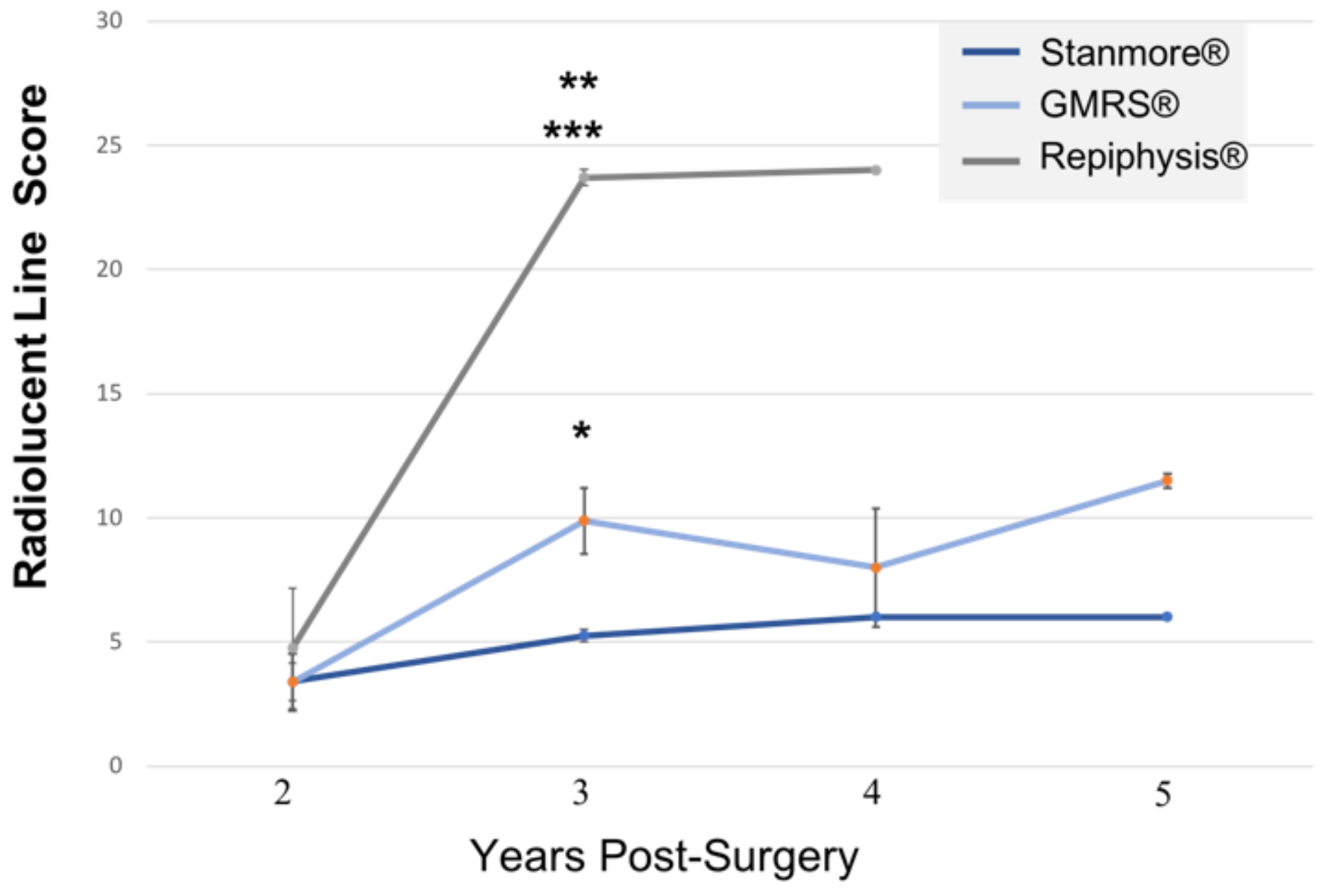

\section{Figure 9}

A graph showing the radiolucent line score in each of the groups over the first 5-year period post-surgery. At 2-years post-operatively, the mean RL score in the Repiphysis ${ }^{\circledR}$ group was $4.75 \pm 2.42$, higher than the $3.40 \pm 0.75$ scored in the Stanmore ${ }^{\circledR}$ group of implants and $2.86 \pm 1.18$ in the GMRS ${ }^{\circledR}$ group. However, no significant differences were found at this time-point. At 3-years post-operatively, the RL incidence had increased in the Repiphysis ${ }^{\circledR}$ group $(23.7 \pm 0.33)$ and was significantly higher than both the GMRS ${ }^{\circledR}$ group (9.88 \pm 1.32 ) and Stanmore $\AA$ group of implants $(5.25 \pm 0.25, p=0.012$ and 0.026 respectively). A significantly increased RL score was measured in GMRS ${ }^{\circledR}$ implants when compared with the Stanmore $\AA$ group $(p=0.008)$. At 5 -years follow up, the RL score had increased to $11.5 \pm 0.29$ in the GMRS $\AA$ group, and $6.00 \pm 0.01$ in the Stanmore ${ }^{\circledR}$ group $(p=0.053) .{ }^{\star} p=0.008,{ }^{* \star} p=0.026,{ }^{\star \star *} p=0.012$. 


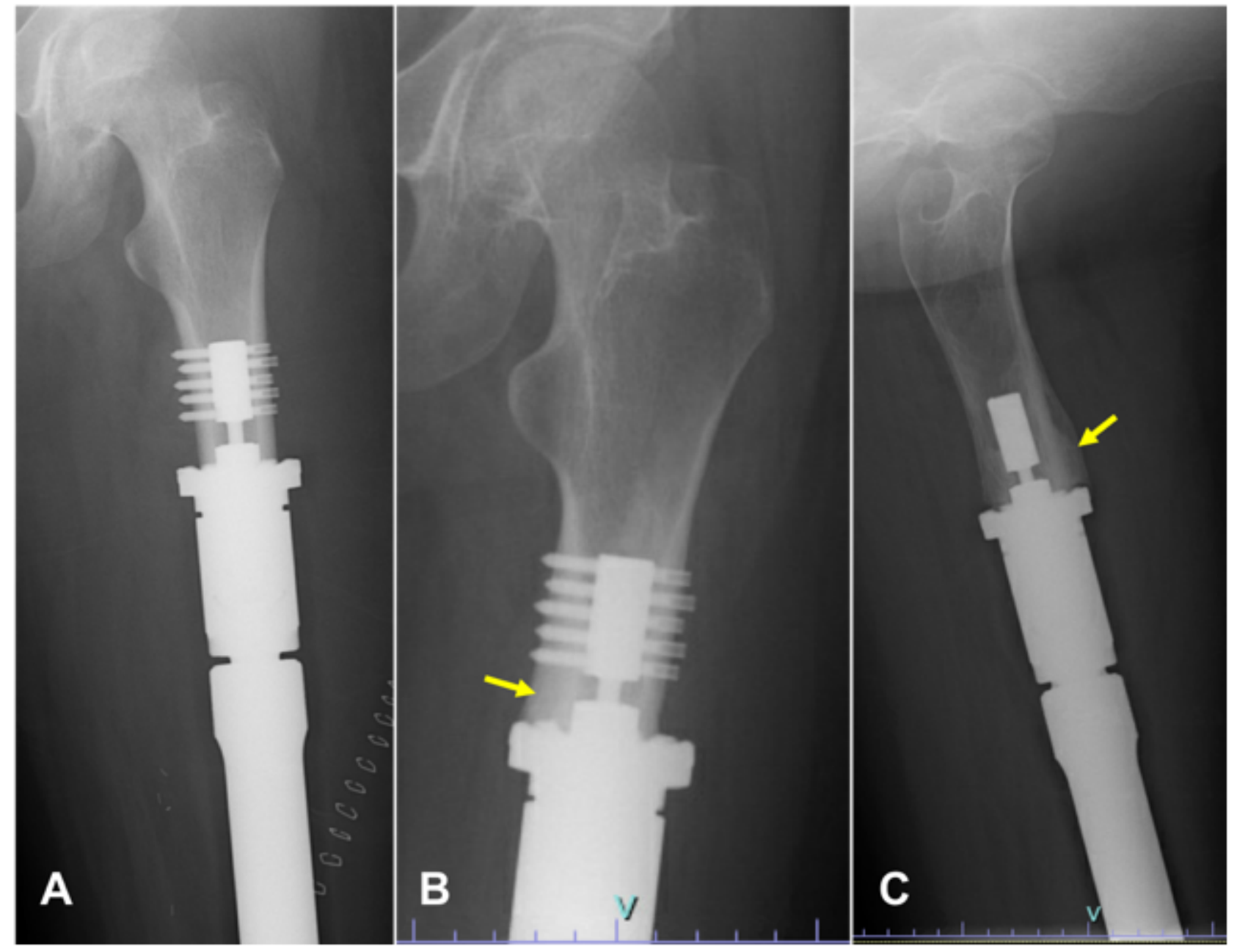

Figure 10

[A] A radiograph of a CPS $\AA$ implant taken immediately post-surgery. [B] The same patient 2-years postoperation showing cortical hypertrophy at the implant shoulder (arrow) in the AP and [C] ML aspect. No cortical bone loss $>1 \mathrm{~mm}$ was evident and no extracortical bone growth was observed in any of the patients.

\section{Supplementary Files}

This is a list of supplementary files associated with this preprint. Click to download.

- Table1to7.docx 